\title{
LA MEMORIA HISTÓRICA DE LA POSTGUERRA EN EL TEATRO DE LA TRANSICIÓN. LA GENERACIÓN DE 1982
}

\author{
Eduardo PÉREZ-RASILLA
}

Universidad Carlos III

\section{RESUMEN}

La denominada generación de 1982, compuesta por dramaturgos nacidos en la década de los cuarenta, ha prestado especial atención en su teatro a la memoria de la postguerra, en la que se inscriben su infancia y su juventud. Esta memoria está dominada por una crítica que se fija principalmente en la propia experiencia autobiográfica, inmediata o ligeramente transmutada, y que prefiere lo menudo y lo íntimo a la mirada sobre los grandes acontecimientos que configuraron el período. Su rechazo de este tiempo histórico no excluye una cierta indulgencia hacia algunos personajes que sobrevivieron como pudieron a tan siniestra etapa.

Palabras clave: teatro, generación de 1982, memoria histórica, transición, postguerra.

\section{ABSTRACT}

The dramatists of the 'generation of 1982', been born in the decade of the forty, have given special attention in his works to the memory of the postwar period, that was the time of their infancy and their youth. Their plays offer a critical look, fixed principally in their own autobiographical experience, and more centered in the intimate world that in the big events of that period.

Key words: Theatre, generation of 1982, historical memory, transition, postwar. 
La incorporación a los escenarios de la generación de $1982^{1}$ trae consigo una nueva mirada sobre la historia reciente de España y una reformulación del concepto de memoria. Los dramaturgos que componen esta generación han nacido inmediatamente después de la guerra civil, por lo que carecen de experiencia propia de aquel suceso determinante, aunque no pueden eludir la herencia que les dejaron en vida sus padres, protagonistas y víctimas de aquella contienda fratricida. Por lo demás, las consecuencias de la guerra civil han condicionado decisivamente a estos futuros dramaturgos durante la infancia y la adolescencia, vividas en los más duros años de la larga postguerra. Ya en los años sesenta, se incorporan a la Universidad, cuando bullen en ella ideas que cuestionan la tradición heredada e impuesta y cuando la agitación estudiantil se constituye en una de las principales formas de oposición a una dictadura que amenaza con perpetuarse. En el proceso de toma de conciencia política, individual y colectivo, tiene mucho que ver precisamente el teatro que se hace en y desde la Universidad y del que muchos ellos participan.

La Transición política sugiere, o exige, la necesidad de revisión, de replanteamiento de la memoria individual y colectiva, y esta generación, que ahora se acerca a la madurez, se siente capacitada para la tarea y moralmente obligada a llevarla a cabo. Así, la memoria histórica se convierte en un tema recurrente en su producción dramática. La posibilidad de plantear las reflexiones ya en libertad y sin la vigilancia de la censura les permite abandonar las fórmulas crípticas, alegóricas o alusivas a las recurrían sus predecesores, obligados por la censura y las demás restricciones políticas y morales, y optar por lenguajes más directos, más personales, más inmediatos, aunque no menos elaborados.

La conciencia de estar escribiendo para un tiempo nuevo implica la duda sobre la propia identidad personal e histórica y, consecuentemente, la necesidad de inventar un lenguaje dramático diferente para comunicarse con una sociedad que está en un febril proceso de transformación y de búsqueda o invención de las propias raíces, que la dictadura había arrancado u ocultado. Sin embargo, esta escritura refleja también las sombras que sobre la sociedad española proyecta la amenaza involucionista, al menos hasta el primer tercio de la década de los ochenta. Tal vez por ello advertimos en muchas de sus propuestas escénicas un cierto tono de perentoriedad y una percepción de la fragilidad personal y colectiva, que se contrapesa con la voluntad decidida de reexaminar el proceso, personal y colectivo, por el cual se ha llegado a la situación histórica presente.

1. Adopto esta denominación, acuñada por el dramaturgo Ignacio Amestoy, a la que he tenido ocasión de referirme en otros trabajos. Como todo marbete, es discutible y de límites borrosos, pero entiendo que resulta útil y razonablemente precisa.

Anales, 21, 2009, pp. 143-159 
Así, se produce una paradoja entre la firmeza con la que se afronta el proceso de recuperación de la memoria y el aturdimiento o el desconcierto que tal situación provoca. Esta paradoja se revela en tantos personajes inseguros, frágiles o menesterosos que pueblan muchos de los textos y que configuran una imagen recurrente, un retrato de unos hombres y unas mujeres definitivamente heridos por una posguerra que no terminan de explicarse.

A partir de estas reflexiones surge la pregunta -implícita o explícita- sobre la actitud ética, estética y política que debe adoptarse. La visión que estos dramaturgos ofrecen de la posguerra es siempre crítica, sin atisbo ninguno de nostalgia. La imagen presentada es sórdida, violenta y cruel, aunque el teatro de estos autores pueda admitir la simpatía hacia algunos personajes o la indulgencia con otros, a quienes considera víctimas de una situación y de quienes, en ocasiones, admira su entereza de ánimo o su capacidad para sobrevivir en circunstancias adversas. La muerte, explícitamente referida, y las ausencias, bien o mal asumidas, configuran un mapa humano incompleto y vulnerado, responsable de una cierta conciencia de amputación, perceptible en las escrituras de estos autores.

Por lo demás, los dramaturgos de esta generación, movidos por la referida necesidad de nuevos lenguajes, adoptan perspectivas diferentes y paradigmas artísticos distintos para enfrentarse a la memoria histórica reciente, aunque se advierte un sustrato común en sus textos, relacionado precisamente con la mirada generacional sobre la que tratábamos en las líneas anteriores. Esta mirada concede una importancia primordial a lo autobiográfico, percibido en ocasiones de manera inequívoca por las referencias explicitas a dichas circunstancias, como ocurre, paradigmáticamente, con El álbum familiar (1982), de Alonso de Santos, o también con ¿Fuiste a ver a la abuela? (1979), de Fermín Cabal. En otras, sin dejar de estar presente, adopta una forma más púdica o más velada, pero tras la que es posible adivinar los ecos de circunstancias familiares o de situaciones con las que el dramaturgo experimenta una singular empatía. Algo así cabe imaginar en textos como Quan la ràdio parlava de Franco, de Benet i Jornet (1979), Yo fui actor cuando Franco (1990), de Ignacio Amestoy, o en determinadas escenas de Terror y miseria en el primer franquismo (1979-2002), de Sanchis Sinisterra, por no citar sino algunos ejemplos. Desde esta consideración, no es extraño que se prefieran los aspectos relacionados con lo privado, lo íntimo o lo cotidiano, aquello, en suma, que cabría considerar como menor desde una perspectiva histórica, a los grandes acontecimientos públicos o a los momentos de especial solemnidad o trascendencia. En definitiva, se da prioridad a la memoria sobre la Historia. Los sucesos históricos o los personajes relevantes aparecen habitualmente en segundo término o funcionan como marco de referencia. 
Una excepción a este procedimiento la encontramos en Dionisio. Una pasión española (1983), de Amestoy, en la que el singular personaje aporta la referencia histórica y simbólica. Se trata de una meditación, distanciada y ponderada, sobre el inmovilismo del régimen dictatorial frente a las tentativas de cambio o de evolución surgidas en sus propias filas. Un personaje histórico concreto y representativo sirve como punto de partida para la construcción de la trama, que reinterpreta con libertad el episodio y lo convierte precisamente en una reflexión sobre la memoria histórica. El material de trabajo se encuentra previsiblemente en la investigación bibliográfica y documental, aunque posiblemente también en el acopio de testimonios obtenidos a través de familiares, amigos o conocidos que pudieron haber sido testigos de aquellos acontecimientos. El tratamiento del tema combina así lo documental con lo ritual, procedimiento en el que se advierten las huellas de Artaud o de Genet, y del que Amestoy se ha servido en algunos de sus textos más logrados. Pero incluso en esta obra, el Ridruejo que se nos presenta no es tanto el influyente personaje histórico, sino un Ridruejo íntimo y ausente, mostrado a través de un ser interpuesto, en una extraña ceremonia fantasmagórica y silenciada.

La guerra civil misma es vista, en casi todos los textos que la recuperan como motivo dominante, también desde una perspectiva íntima, aparentemente modesta y casi marginal. No hay ánimo de ofrecer una visión totalizadora, sino, por el contrario, una voluntad de captar detalles reveladores que hasta el momento han podido pasar inadvertidos. Las obras de los dramaturgos de esta generación que tratan sobre la guerra civil devienen en una reflexión sobre la memoria, que se impone de nuevo sobre la Historia. Así sucede con Cavalls de mar, de Josep Lluís y Rodolf Sirera, con Gernika, un grito. 1937 y El chófer del teniente coronel von Richthofen toma decisiones, de Ignacio Amestoy, o, sobre todo, con iAy, Carmela!, de José Sanchis Sinisterra, en la que la apelación a la necesidad de conservar la memoria se hace explícita y se convierte en una suerte de programa, casi de manifiesto o, al menos, de toma de posición.

El personaje de Carmela atraía las simpatías del espectador precisamente por su mirada ingenua, sincera y carente de un planteamiento ideológico formal previo. Tan sólo existe en ella, eso sí, una conciencia social, fruto del hambre y el desprecio que los suyos han padecido durante generaciones y que se traduce en una aversión al caciquismo y a las sangrantes desigualdades sociales: "Con la ración de miseria que nos tocó en la vida... Y aún decía doña Antoñona, la cacica: "Qué fuerza tienen los pobres, todo el día segando con sólo un limón y un par de algarrobas y nunca se mueren”» (¡Ay, Carmela!, 106). Pero Carmela no adquiere una estricta conciencia política en vida: no es capaz de elaborar un discurso, por sencillo que sea, que sustente su desazón, ni de formular un pensamiento reivindicativo. Nunca sobrepasa los límites de su sensibilidad solidaria, 
generosa y capaz de abarcar a todos aquellos de cuyo sufrimiento tiene noticia, que le impulsa a confraternizar con los perdedores, con los derrotados por la vida, con los muertos. Será precisamente en los territorios de la muerte donde adquiera una conciencia política precisa.

La muerte de Carmela, injustamente padecida como consecuencia de su fraternidad con el vencido, en nombre de una simpatía que traspasa fronteras y barreras ideológicas, se transforma en metonimia de la causa republicana, pasada por las armas de unos militares despóticos y brutales, tal como sugería la imagen que, no del todo conscientemente, compone Carmela al ser utilizada como blanco de las tropas facciosas: vestida con una improvisada bandera republicana, esta resbala sobre su cuerpo y deja al aire sus pechos, indefensos ante las balas. Pero la muerte no convierte a Carmela en una mujer sectaria, ni siquiera en alguien con deseos de venganza, sino en portavoz de la memoria, una memoria íntima, ajena de nuevo a los grandes discursos, pero no indiferente con el sufrimiento de los seres humanos, ni con el dolor o con la muerte. De ahí la necesidad dramática de que Carmela regrese del territorio de la muerte para recordar a Paulino lo que sucedió y lo que puede seguir sucediendo si se olvida, «porque los muertos no escarmentáis ni a tiros» (¡Ay, Carmela!, 157). Y el propio Paulino, consciente o no de ello, comienza a convertirse, pese a su traición íntima a Carmela y a los criterios que han regido su propia vida, en memoria de esa incipiente y amenazadora posguerra, marcada ya por la sangre, la intimidación y la humillación y el halago servil como formas de supervivencia y de ascenso social. Así, buena parte de la eficacia dramatúrgica del texto hay que buscarla en la deliberada y drástica reducción de la guerra civil a estos dos humildes y frágiles personajes, a vueltas con sus recuerdos, lo que constituye un paradigma generacional respecto al tratamiento de la memoria histórica.

Fernando Fernán Gómez, que escribe su obra en la década de los ochenta, pero que pertenece a una generación anterior, logra su gran triunfo como dramaturgo con Las bicicletas son para el verano, una historia sobre la guerra civil vista desde la perspectiva de un adolescente. No parece abusivo pensar que el éxito de público obtenido por Las bicicletas son para el verano tiene mucho que ver justamente con la novedad de la mirada ofrecida, con la atención a lo cotidiano y a lo menudo, y con la dosis de humor y ternura que se proyecta sobre sucesos terribles. El relato de los grandes acontecimientos queda en un segundo término, porque se supone ya conocido por un público que puede encajar los avatares de los personajes del drama en la historia de la guerra civil. Fernán Gómez se servía, sin duda, de sus propios recuerdos de la guerra a la hora de componer Las bicicletas son para el verano, aunque la trama de la obra no se ajuste a sus circunstancias biográficas, sino que discurra por los caminos de la ficción.

Anales, 21, 2009, pp. 143-159 
Pero el corpus dramático relativo al recuerdo de la posguerra es superior en cantidad al teatro dedicado a la guerra civil, circunstancia que resulta ya reveladora y que refleja un cambio de intereses temáticos. La memoria personal se convierte también en instrumento para abordar el análisis crítico de la posguerra. El recuerdo que se conserva de unos acontecimientos vistos desde la mirada infantil y adolescente, que transcurren en el marco de una dictadura que vive todavía años muy negros, aparece, como ha quedado dicho, en textos como: ¿Fuiste a ver a la abuela?, de Fermín Cabal, y El álbum familiar, de José Luis Alonso de Santos. Estas dos obras reflexionan sobre el proceso de formación personal a través de un simbólico viaje iniciático, más evidente en el caso de El álbum familiar figurado mediante un desplazamiento en tren que combina un estilo hiperrealista con una dimensión onírica, pero perceptible también en el inquieto ritmo de los recuerdos, los sueños, los miedos y las imágenes de ¿Fuiste a ver a la abuela? Ambas utilizan una misma concepción formal, basada en una estructura fragmentada, con constantes alteraciones espacio-temporales, que responden a las categorías de la memoria y no a las del relato convencional estructurado según la tradición retórica clásica.

La revisión de aquellos episodios autobiográficos y cotidianos condicionados por la dictadura tiene un cierto carácter liberador, tras un proceso de doloroso autoconocimiento. La posguerra es vista como una constricción en lo vital, como una sucesión de temores a lo desconocido, como una educación represiva y atemorizadora. En este proceso educativo, la religión parece dominarlo todo y cualquier actividad, inquietud o deseo, ajenas a ella, se convierte en algo clandestino. La figura paterna, obligado modelo para los niños y adolescentes, se nos muestra con una personalidad acobardada y difusa, ajena a los suyos, marcada por el desánimo, el desconcierto y la derrota, lo que explica el desvalimiento y hasta la sensación de orfandad de los jóvenes que se educaron en aquellos años. Este sentimiento de orfandad no se circunscribe exclusivamente a los textos relacionados directamente con la memoria histórica de la posguerra, sino que se convertirá en motivo recurrente de una escritura dramática plagada de jóvenes desprovistos de una referencia moral próxima, inmersos en un mundo en el que sus padres no tiene cabida, bien porque estos parecen haberse desvanecido o bien porque los mismos jóvenes los han expulsado de su territorio, avergonzados de su conducta. Con frecuencia estos personajes son propiamente huérfanos, en otros casos lo son moralmente: prefieren el olvido o la renuncia a admitir su filiación. En algún caso extremo, existe en ellos una expresa conciencia de seres malditos ${ }^{2}$.

2. Son muchos los textos en los que podemos encontrar ejemplos poderosos de esta sensación de orfandad. Su estudio desborda las pretensiones de este trabajo. Por citar tan sólo dos ejemplos muy significativos, podemos recordar Bajarse al moro, de Alonso de Santos, y Ederra, de Amestoy. 
Volviendo a las dos obras que ahora nos ocupan, sus personajes protagonistas son dos jóvenes que miran a sus respectivos padres con perplejidad, como si fueran inquietantes misterios cuyo último sentido se les escapara. Advertimos un significativo paralelismo entre las imágenes del padre ofrecidas en ¿Fuiste a ver a la abuela? y las que se muestran en El álbum familiar. En ambas, el padre es un ser vencido, atemorizado por la vida, incapaz de servir de modelo o de referencia para sus hijos, o de proporcionarles un magisterio o un estímulo para su existencia. El padre se ha convertido en una víctima del papel que la sociedad le obliga a representar.

MIGUEL: A papá no hay quien le aguante.

ANTONIO: Papá jamás disfrutará de la vida

MIGUEL: Papá nunca dice mentiras.

ANTONIO: Papá nunca cuenta chistes.

MIGUEL: Papá cuando somos malos nos castiga

ANTONIO: Miguel, ¿quién es papá?

MIGUEL: Papá es un señor que por las mañanas se pone el bigote y se marcha.

(¿Fuiste a ver a la abuela?, 82)

MI PADRE: No tengo ganas de sonreír. Nunca en mi vida he tenido ganas de sonreír. Me he pasado la vida matándome a trabajar, haciendo siempre lo que no quería hacer pero tenía que hacer. No quiero sonreír, y no voy a sonreír, jleche! Quiero que cuando mi hijo mire esta foto, me vea así, como soy, la verdad. En este tren, en este tren que nos lleva, esperando que venga el revisor y tener que humillarme una vez más, pidiéndole perdón por estar haciéndonos esta foto sin permiso de nadie.

(El álbum familiar, 73)

Así, no es extraño que se ofrezca a los niños una visión confusa y enigmática de la guerra y de su contexto político, traspasada por vagos temores y entrecruzada por una suerte de mitología infantil. Los mayores imponen sobre ella un silencio que revela su inquietud y su desasosiego. Esta memoria de la desmemoria es un motivo recurrente en los textos a que nos referimos:

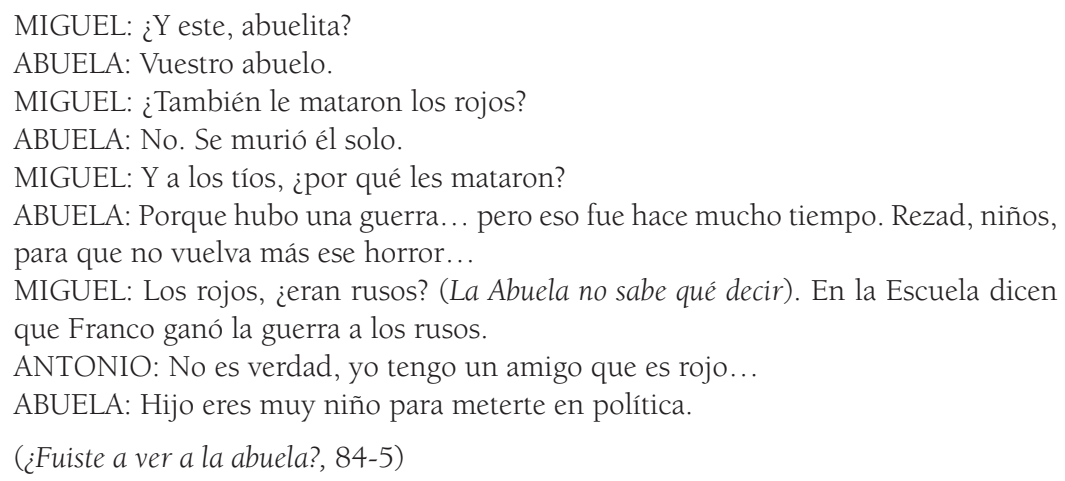

Anales, 21, 2009, pp. 143-159 
ZAPATERO: ¿Quieres algo, chaval? (Silencio) ¿Te comió la lengua un gato?

ANTONIO: (Tímido) ¿Usted es un rojo?

ZAPATERO: (Tras una pausa) ¿Quién lo dice? (Silencio) Bueno, pasa... pasa, hombre.

¿Tienes miedo?

ANTONIO: A mis tíos los mataron los rojos.

ZAPATERO: ¿Sí ¡Qué te parece! Tuvieron poca suerte. A mí en cambio me fusilaron los moros y aquí me tienes...

ANTONIO: Eso no puede ser verdad.

ZAPATERO: No soy un fantasma, ¡toca! ¿O crees que miento? Está bien, si no hay más remedio te contaré esta historia... pero tienes que jurar que guardarás el secreto, ¡cómo esto llegue a oídos de Franco!

(¿Fuiste a ver a la abuela?, 86)

ANTONIO: Abuela, Enriquín dice que su abuelo era rojo...

VECINO: ¿Te quieres callar! (Torta a Enriquin)

(¿Fuiste a ver a la abuela?, 110)

MIGUEL: Papá, ¿tú mataste algún rojo? (El padre lo mira asombrado) ¡A que sí!

ANTONIO: ¡A que no!

PADRE: No sé, hijos, no me acuerdo. Anda, iros a jugar.

MIGUEL: Pero a los tíos los mataron... ¿Tú no se la devolviste?

PADRE: Claro, hijo. Hice lo que pude.

MIGUEL: Entonces alguno matarías...

PADRE: Les tiré, pero no sé si les di...

MIGUEL: Seguro que les diste.... ¿Y Franco mató a muchos?

PADRE: A todos los que pudo, Miguel. Había que castigarles.

MIGUEL: Como cuando tú nos pegas, ¿verdad?

PADRE: Algo así.

ANTONIO: ¿Y qué habían hecho malo?

PADRE: Pero, ¿por qué me preguntáis todo esto? ¿Para qué está la escuela, qué os enseñan allí?

(¿Fuiste a ver a la abuela?, 111)

ENRIQUÍN: Pues mi abuelito era rojo.

MIGUEL: Sería un criminal...

ENRIQUÍN: Era jefe de estación... del tren...

MIGUEL: Al mío lo mataron los rojos...

ENRIQUÍN: ¡A lo mejor mi abuelo mató al tuyo!

(¿Fuiste a ver a la abuela?, 111)

La figura del dictador se entrevé apenas a través de la vida cotidiana de los personajes. Si bien se yergue como un ser omnipresente, que se inmiscuye en la vida de todos, se le mira de una manera despectiva y distante. A diferencia de lo que ocurría en el teatro de la generación anterior, en el que la figura del dictador, encubierto tras diferentes máscaras que no querían velar su naturaleza despótica ni ocultar su semejanza con el siniestro general, se mostraba hasta la 
hipertrofia, los nuevos dramaturgos lo recuerdan como un estribillo reiterativo, pero carente de sentido. En la escena segunda de El álbum familiar, mientras la familia protagonista viaja en el tren, oímos fragmentos tópicos de los discursos de Franco, que se repiten como si remedaran el monótono traqueteo del propio tren, pero también la machaconería de unas consignas vacías, repetidas hasta la saciedad, como imagen de una España inane y aburrida, carente de perspectivas y abocada a escuchar una única voz.

VOZ DE FRANCO y los raíles: «...españoles... españoles...españoles... españoles...» (...)

VOZ DE FRANCO y los raíles: «... la patria exige sacrificios... sacrificios... sacrificios...»

VOZ DE FRANCO y los raíles: «... los enemigos nos acechan... nos acechan... nos acechan...»

VOZ DE FRANCO y los raíles: «... en este viaje en que estamos todos comprometidos, llevaremos a la patria cueste lo que cueste... cueste lo que cueste... cueste lo que cueste...» (El álbum familiar, 65-6).

El álbum familiar aporta además otros elementos de interés desde el punto de vista de la memoria histórica: Falange como sostén ideológico, simbólico y estético del franquismo, pero también como factor de disidencia, que reclama al general la famosa revolución pendiente y que, sobre todo, reprocha al dictador su responsabilidad en la muerte de José Antonio, fundador y figura mítica en el imaginario colectivo de un segmento de la sociedad española más concienciado con su ideario político. Desde ella se muestra la imagen de un Franco sanguinario y cínico, insensible y capaz de todo con tal de conservar el poder, ofrecida desde sus propias filas y no desde la de los enemigos.

MI PRACTICANTE: ¡Asesino! ¡Asesino! ¡Por ti murió el tío santo de esta familia! ¡Tú no quisiste canjear a los prisioneros! ¡Tú los mataste a todos! ¡Por tu culpa murió también José Antonio Primo de Rivera! ¡Él habría salvado a la patria! (El álbum familiar, 68).

El practicante falangista culmina la soflama con el previsible canto del Cara al sol, esgrimido como afirmación de partido, pero también como reivindicación de un anacrónico ideal en el que algunos siguen creyendo ciegamente.

En segundo lugar, la presentación de otra iconografía característica del franquismo: el sacerdote fusilado. La construcción de la mitología del franquismo pasa por esta profusa ostentación de los mártires de la persecución religiosa, presentada como causa principal de la propia guerra y de la represión posterior, pero también como símbolo, como divinidad familiar protectora, como signo de identidad y de orgullo, y, desde luego, como salvoconducto o garantía de fidelidad o afección al régimen. La mirada del dramaturgo está empapada de humor negro, que apunta precisamente hacia la obsesión por las reliquias y la muerte, 
por la hipertrofia del sentimiento religioso, convertido en burda caricatura de sí mismo:

MI PRACTICANTE: Son gente de confianza. Yo les conozco de toda la vida. A los chicos los he visto nacer. Él estaba con los nacionales. A su hermano lo mataron en la guerra, lo fusilaron los rojos. Era cura. Ahora es santo. Tiene un dedo incorrupto en alcohol, Le ha crecido la uña, sabe usted, sí, sí. Yo lo he visto. Si quiere les pregunto si lo tienen a mano y se lo pueden enseñar (El álbum familiar, 80).

La figura del sacerdote funciona además en estos textos como metonimia de la obsesión religiosa, que todo lo invade y todo lo condena, singularmente lo relativo al sexo, aunque sus actitudes no carezcan de ribetes paternalistas y, en ocasiones, rijosos y equívocos. Frente a lo que el cura dice y representa, emerge el deseo sexual incipiente, signo a su vez de la propia individualidad, del descubrimiento del yo frente a las trabas impuestas:

ANTONIO: (...) Padre, me acuso de no haberme portado bien (El cura asiente con impaciencia) ni con mis padres ni con mis profesores...

DON RAIMUNDO: ¡Al grano! ¿Cuántas veces te has tocado?

ANTONIO: Trece, don Raimundo, desde el viernes pasado.

DON RAIMUNDO: Te quedarás en los huesos, bribón (le pellizca) ¿Qué más, lo gordo, lo gordo...

ANTONIO: He oído a mis padres en la cama

DON RAIMUNDO: Oído o visto

ANTONIO: Oído

DON RAIMUNDO: Mal, muy mal... (Menea la cabeza) Dime, hijo. ¿Y te gustó?

(¿Fuiste a ver a la abuela?, 80).

SACERDOTE: Oigan. ¿Ustedes son los de la adoración nocturna? (...)

MI PADRE: Mire, estamos ahora celebrando el cumpleaños de la niña, no me parece el momento adecuado para..., además están las maletas...

SACERDOTE: Mejor que mejore, iverdad, pequeña? Podemos celebrarlo así. Voy a ponerla aquí en cruz y ustedes rezarán por turno ante ella durante toda la noche hasta que venga su tren (El álbum familiar, 89).

No faltan tampoco, vistos desde la perspectiva del niño, otros estereotipos de la España franquista: la pareja de la guardia civil que custodia al preso, en una estampa siniestra, pero no exenta tampoco de un cierto paternalismo. O el revisor del tren, o la sala de espera, metonimia y metáfora de la España mediocre de la dictadura.

Otros textos prefieren una mirada panorámica sobre una larga etapa de la posguerra, vista a través de personajes ficticios, representativos del período, con ánimo de reflexión o de balance sobre lo que supuso la dictadura para los ciudadanos que la padecieron o para los que se beneficiaron de ella. El procedimiento admite referencias a personajes o a acontecimientos históricos que proporcionan el contexto de la fábula, pero, sobre todo, permite establecer una relación dialéc- 
tica entre lo oficial y lo real, entre lo público y lo privado, entre la grandilocuencia retórica del sistema y el lenguaje humilde de las gentes que lo soportan. Así sucede con textos como Quan la ràdio parlava de Franco, de Benet i Jornet, con aportaciones de Terenci Moix, y con Terror y miseria en el primer franquismo, de Sanchis Sinisterra (proyecto comenzado en 1979 y culminado en 2002).

En las obras de este apartado, la memoria presumiblemente se nutre de la información bibliográfica y documental, pero también del propio recuerdo personal o de las informaciones que han podido proporcionar gentes próximas a los dramaturgos. Desde la perspectiva de la composición formal, en el texto de Sanchis es evidente la influencia brechtiana, desde un título concebido como homenaje al maestro, aunque sin renunciar a otras presencias -Beckett, por ejemplo-, ni a la libertad estilística y compositiva que le es característica. En la obra de Benet i Jornet, no exenta de la huella brechtiana, predomina una depurada estética neorrealista que el dramaturgo ha cultivado en una parte significativa de su obra.

Quan la ràdio parlava de Franco plantea un recorrido histórico desde 1947 a 1975 en el ambiente de un barrio popular barcelonés. La circularidad de la escritura, que parte del 75 para remontarse al 47 y retorna, a través de determinados acontecimientos históricos, al momento en el que se produce la noticia de la muerte del dictador, sugiere ya un planteamiento dialéctico, que se confirma con la utilización del recurso que sirve como leit motiv: la radio. El contrapunto entre los acontecimientos públicos, anunciados a través de la radio u omitidos en sus informaciones, y las vidas privadas de los personajes elegidos, aporta el elemento más original en este texto, reforzado por la circunstancia de que los personajes se expresan en lengua catalana, mientras la radio emite exclusivamente en castellano. Por lo demás, el contraste se acentúa al advertir la diferencia entre el ampuloso, retórico y huero lenguaje oficial en el que peroran las campanudas voces de los locutores y el estilo llano e incisivo en el que hablan los personajes.

La primera escena del drama transcurre el 21 de octubre de 1975. Tras escuchar el comunicado en el que la Casa Civil del Jefe del Estado informa de la enfermedad del general y de su pretendida recuperación, Remei expresa sus miedos y repite maquinalmente los tópicos de la propaganda franquista sobre la tranquilidad del país durante el largo período de su mandato. A lo que su sobrino replica:

FELIU: Amén, tieta. Això és una de les històries possibles de la pau, de l'època més gloriosa que mai no havia viscut la nostra terra, segons ens deia la ràdio a totes hores. Això és la història d'uns anys, d'un lloc i d'una gent. Els anys són aquells que van començar pel gener de 1939, el lloc el formaven carrers barcelonins de dintre muralles, estrets i llardosos; la gent era la que vivia allí, que intentava sobreviure a la 
postguerra... Això és una comèdia sobre el temps i la memòria; en el record el barri no és com avui, sorollós i amb antenes de televisió, sinó igualment mesquí i potser sense glòria, però només amb una ràdio per cada tres veïns. Puc començar recordant un d'aquells matins, a l'hora que el barri despertava, el dia que hi vaig arribar. Un dissabte de juliol de 1947 (Quan la ràdio parlava de Franco, 24).

Los personajes de la obra, reducidos a un estrecho círculo de vecinos del barrio, no encarnan propiamente estereotipos, aunque sí representan actitudes y posiciones diferentes y significativas ante la dictadura. El personaje de Cases evoca la militancia franquista fanática, prepotente y grosera, que le permite disponer de recursos económicos, de una querida deslumbrante o de las voluntades de las gentes sencillas, mediante la intimidación o mediante las pequeñas y humillantes compensaciones: una recomendación, una pequeña propina, etc.

CASES: Ara, tan alt que se't rebentin els pulmons, vull que cridis. ¡Viva Franco!

(Pausa. El sacseja, amenaçant) ¡Viva Franco! (Quan la ràdio parlava de Franco, 40).

El de Remei dibuja a la mujer sin conciencia política, temerosa, que acusa el impacto de la propaganda franquista, que la convierte, más por miedo que por convicción, en una defensora del régimen dictatorial. Otros, sin embargo, ejemplifican una clara conciencia política, adquirida en la Universidad (Feliu), en el trabajo (Pere) o en la pasada, pero inolvidable, experiencia republicana (Jaume).

Y, paralelamente a ellos, el lenguaje altisonante y falso de la radio, cuyo uso, como explicaba Feliu en la escena inicial, a diferencia del empleo individual y privado que hoy podemos hacer de ella, es colectivo y establece un vínculo entre los personajes que la escuchan. La radio es colectiva también en cuanto voz pública de un régimen que proclama y silencia acontecimientos. Así, la radio no hablará de la huelga del 51, que tomó como motivo desencadenante la protesta contra la subida del precio del billete del tranvía, pese a que agitó la vida de la ciudad, pero cubrirá con profusión el Congreso eucarístico del 52. El tono relamido e hiperbólico, encomiástico hasta el servilismo, del locutor pone en evidencia no sólo el maridaje entre el poder político y el eclesiástico, que convierten el congreso en una ceremonia de exaltación e intimidación, sino también el abismo entre aquella manifestación de poder, con su desmesurado aparataje retórico, y la modesta vida cotidiana de los personajes de la obra:

No tengo palabras para describir lo indescriptible, para comunicar a los oyentes esa suprema coalición de humildad, de dignidad, de santidad... Barcelona vive un momento único, trascendental en su historia. Miles de gargantas unen sus preces por una ciudad dinámica, moderna pero eterna, renovada pero más católica que nunca, más agradecida que nunca a un hombre que la ha convertido en lo que es, y que en esta ocasión la honra y la alienta con su presencia: ¡Francisco Franco, caudillo de España! (Quan la ràdio parlava de Franco, 70). 
La intención crítica busca su camino en la construcción técnica del drama, en la elección de los materiales escénicos, pero mantiene una distancia respecto a los personajes y acontecimientos, como si el dramaturgo se limitara al papel de cronista de una realidad compleja y no carente de pliegues. La deliberada huida de cualquier discurso panfletario u obvio proporciona una sensación de objetividad en el análisis, lo que no significa indiferencia o falta de compromiso, sino rigor dramático y, a la larga, eficacia en el discurso crítico. Por ello, la construcción de los personajes responde a un intento de comprensión. Ni hay ensañamiento con aquellos que manifiestan alguna clase de adhesión al franquismo -incluso Cases aparece dotado de detalles de humanidad- ni se idealiza a aquellos que combaten la dictadura, sino que se ahonda en sus contradicciones o en sus insuficiencias. El resultado del proceso es abierto y podría proporcionar unos materiales para el debate, una propuesta de análisis de la incidencia de la dictadura en la vida cotidiana.

Algunas semejanzas con este procedimiento presenta Terror y miseria en el primer franquismo, de Sanchis Sinisterra. Como en el texto de Benet i Jornet, se proporciona una visión panorámica, dilatada en el tiempo, de la vida cotidiana en la España de la dictadura, y figuran como telón de fondo personajes y acontecimientos históricos que, desde la distancia, condicionan inevitablemente las vidas de tantos seres humanos. Pero Terror y miseria en el primer franquismo muestra algunas diferencias respecto a Quan la ràdio parlava de Franco. El ámbito de la acción no se reduce a un solo barrio, sino que se extiende por espacios muy diversos, no siempre definidos ni localizados con precisión, pero entre los que figuran ciudades como Barcelona, Valencia, Madrid, México, etc. Como en el modelo brechtiano de referencia, cada escena cuenta con sus propios personajes y la unidad de la acción no viene dada ni por el espacio, ni por la continuidad de la trama ni por las trayectorias de estos personajes, sino por el marco histórico en el que personajes y acciones se ubican. La forma de composición se basa en la contigüidad de los episodios y no en su trabazón como integrantes de una trama, lo que proporciona una estructura abierta, a la manera brechtiana, decisión a la que no es ajena la ocasión para la que el texto se escribió. La consecuencia es una obra que recorre algunas de las situaciones más significativas y más terribles de los primeros años de la posguerra a través de nueve historias diferentes. La omnipresencia de la muerte, la supresión de la libertad de cátedra, la retórica huera del régimen para encubrir una realidad mezquina, los desaparecidos, la exaltación de la violencia, la cárcel, el exilio, la necesidad del ocultamiento y la aparición de ventajistas grupos de poder al socaire de los valores religiosos y el oportunismo integrista e hipócrita son los temas que configuran este mapa trazado en Terror y miseria en el primer franquismo, a los que se suman otros motivos, 
como la decepción por la indiferencia internacional por la situación española, el desvalimiento de una juventud educada en los valores de la dictadura, el aislamiento y la soledad individuales y colectivos, etc.

La mirada que Sanchis proyecta sobre los acontecimientos responde también al modelo brechtiano, lo que permite al dramaturgo utilizar diversos estilos y registros. En ocasiones recupera, a veces literalmente, testimonios de época, lo que conduce a un tratamiento cercano al del teatro documento, combinado con una notable dosis de lirismo (Intimidad); en algunas escenas se permite un humor cáustico, incluso farsesco, que ridiculiza personajes y situaciones (principalmente en Plato único y en Atajo, aunque asoma también en más escenas); en otras, las situaciones adquieren carácter tragicómico (Filas prietas, El sudario de tiza); en otras más, la composición responde a patrones de condición propiamente dramática (El anillo, El topo), en alguna se entremezcla lo documental, lo dramático, lo lírico y hasta lo onírico (Dos exilios) y, en la que abre el espectáculo (Primavera 39), se recurre a una estética en la que advertimos ribetes surrealistas, expresionistas y simbolistas.

En todas ellas el lenguaje es incisivo y directo, y el discurso crítico, trasparente y acerado, con momentos de fuerte intensidad poética y emocional o con situaciones disparatadas e hilarantes, como la de Plato único, en la que el propietario de un comercio de accesorios relacionados con la electricidad anuncia su establecimiento con una paráfrasis del famoso lema de la dictadura: «POR EL AMPERIO HACIA DIOS» (Terror y miseria en el primer franquismo, 110) como las que abundan en Atajo, referencia burlesca al autor de Camino, trazada a su vez como homenaje al humor de La Codorniz. Pero no se evita tampoco la referencia a asuntos incómodos, como el enfrentamiento entre facciones políticas distintas en el bando republicano o las actitudes diversas ante el yugo insoportable de la dictadura. No prescinde Sanchis de la intención brechtiana de que las situaciones sirvan de base para la discusión y la toma de conciencia, lo que se pone de manifiesto precisamente en las escenas más abiertas y más inquietantes, como Dos exilios, Intimidad, El topo, Primavera 39 o El sudario de tiza.

TERESA: Intimidad, Nati. ¿Sabes lo que es eso? Aquí, oliéndonos el culo unas a otras todo el santo día... y aún más por la noche; amontonadas como animales para dormir, y en manada de un lado para otro, para trabajar, para comer, para cagar... Tener por lo menos un pequeño rincón de una misma que las otras no puedan tocar, ni ver, ni oír... Los sueños, por muy horribles que sean. Algo privado, sí... y es gracioso que yo lo diga. Privado. ¿Lo entiendes?

NATI: Lo del culo no lo dirás por mí, que me lo lavo cada día... (Transición). No, no lo entiendo. Yo me conformo con aguantar aquí, y entera, si puede ser, todo lo que haga falta. A ver si mientras llega un indulto...

TERESA: Un indulto...

NATI: ¿También le haces ascos? Pues, ¿sabes lo que decías soñando?

Anales, 21, 2009, pp. 143-159 
TERESA: No me importa.

NATI: No te importa, ¿eh? ¡Pero te conviene saberlo!

TERESA: ¡Te digo que te calles!

NATI: Sólo se entendía una palabra, una sola: «Perdón». ¿Te enteras? Perdón, perdón, perdón... Eso decías.

TERESA: (Tras una pausa, débilmente) No has debido decírmelo. (Silencio) Di, ¿qué ganabas?

NATI: Era tu intimidad, ¿no? Pues para ti. A mí no me gusta quedarme con lo que no es mío. No soy una ladrona (Sanchis Sinisterra: Terror y miseria en el primer franquismo. Intimidad, 141).

En Yo fui actor cuando Franco, Amestoy propone un tercer modelo dramático para la recuperación de la memoria, que, en cierto modo, combina los rasgos característicos de los dos estudiados anteriormente. Como en El álbum familiar o como en ¿Fuiste a ver a la abuela?, un personaje reconstruye los episodios que han configurado su vida, desarrollada a lo largo de la posguerra, y presta espacial atención a aquellos sucesos que tuvieron para él un carácter iniciático. Pero, a diferencia de lo que sucedía en aquellos textos, el protagonista de Yo fui actor cuando Franco, Manuel, no es un hombre en el umbral de la madurez, sino una persona de la generación anterior, que ha cumplido ya los sesenta y a quien han diagnosticado una enfermedad mortal a corto plazo -el VIH-, por lo que ha decidido poner término a su vida, tras haber acompañado al aeropuerto a su pareja, un hombre joven que realiza una suerte de viaje iniciático a Nueva York con el dinero que le ha proporcionado Manuel. La mirada retrospectiva no es, por tanto, la del hombre que hace balance de su juventud en la etapa en la que comprende que le llega el momento de asumir responsabilidades públicas, de participar en la construcción de la sociedad, sino la de quien abandona esa sociedad después de entregar el testigo a quien encarna para él un futuro lleno de promesas. El dramaturgo no transmuta sus propias experiencias autobiográficas, sino que, presumiblemente, ha manejado informaciones documentales y tal vez relatos de personas con las que ha trabado algún conocimiento.

Por otra parte, la composición de Yo fui actor cuando Franco permite presentar un panorama de la dictadura, como ocurría en los textos de Benet i Jornet y de Sanchis Sinisterra, con sus referencias a la represión policial -eficaz y obsesivo leitmotiv en esta obra de Amestoy-, a la corrupción económica del régimen, a la censura y a la inanidad intelectual, a la sordidez y a la hipocresía moral, a las penurias económicas y vitales de buena parte de la sociedad o, sobre todo, a diversos acontecimientos de la vida teatral, y a la incidencia que todo ello podía tener sobre un hombre desvalido como el protagonista. Pero, a diferencia de aquellos textos, la mirada ofrecida no es la que el dramaturgo proyecta sobre un segmento de la sociedad, sino la visión del propio personaje, consciente de que su condición -homosexual, de pasado familiar republicano y de inequívocas 
convicciones políticas izquierdistas- lo convierte permanentemente en un ser sospechoso y perseguido, incluso cuando la incipiente democracia ha sustituido presumiblemente a la dictadura.

La especificidad de la circunstancia de Manuel condiciona la singularidad de su mirada, que encuentra el molde dramatúrgico adecuado en el monólogo, al que no le faltan ribetes brechtianos ni una deriva ceremonial, tan propia del teatro de Amestoy. El personaje tiene como mudo interlocutor a su madre, fallecida cuando él era todavía un niño y con quien permanece unido por un oscuro vínculo afectivo y erótico, lo que justifica un tono irónico y cómplice, significativamente comprensivo y carente de amargura, aunque sus experiencias, que recuerdan a las de algunos personajes desdichados de la novela española clásica y contemporánea, proporcionaran motivos más que suficientes para el resentimiento. Sin embargo, el espectador comprenderá que Manuel es una víctima de la derrota de una causa -la causa de la República y, por extensión, la causa de la libertad-y de la arbitrariedad brutal, mojigata y excluyente de una interminable posguerra. Y comprenderá también cómo la bonhomía de Manuel es la consecuencia de su memoria, implícitamente reivindicada también en Yo fui actor cuando Franco, desde la conciencia de lo que todo ello ha significado en la vida del personaje o, mejor aún, de lo que el singular coraje de Manuel ha supuesto en un medio como aquel en el que le ha tocado bandearse: «Ellos saben quién soy, y yo también sé quién soy» (Yo fui actor cuando Franco, 49).

Sin embargo, la ironía, en ocasiones entrañable, y la entereza del personaje ante la adversidad no impiden la precisión contundente de la denuncia:

Nos llevaron a los calabozos de la Dirección General de Seguridad. Un día, cuando me pasaban de un pabellón a otro, para aquellos absurdos y crueles interrogatorios, vi al tío Gabriel. Fue la última vez que le vi. Me humillaron, madre. Como uno no imagina que se puede humillar a un ser humano. Lo hicieron. Nunca pude, ni remotamente, intuir que los policías tuvieran tanta imaginación (Yo fui actor cuando Franco, 38-39).

Ni tampoco la precaución, que mira con cautela la nueva situación, porque atisba tras ella los fantasmas del pasado, sensación recurrente en los dramaturgos de la generación, que en la obra de Amestoy se hace explícita con alguna frecuencia:

No hay que temerles tanto. Todos tenemos nuestros derechos. No es como antes. Soy abogado. ¿Trae la orden del juez? Aunque les importe muy poco. Fíjate lo que cuentan los periódicos. ¿Y lo que no se cuenta! Cuando quieren algo, no reparan en nada. Ni en nadie. Y quieren acabar con nosotros. Sí, madres. ¿Sabes? Conservan todas las fichas de entonces. No las han destruido. Con la menor disculpa, nos atacarán. Todo está preparado. Y ocurrirá el día menos pensado. Los guardianes. Los guardianes son los más peligrosos (Yo fui actor cuando Franco, 26). 


\section{BIBLIOGRAFÍA}

ALONSO DE SANTOS, José Luis (1992), El álbum familiar, Bajarse al moro, Madrid, Espasa-Calpe (Ed. de Andrés Amorós).

AMESTOY, Ignacio (1983), Dionisio, una pasión española, Madrid, Akal. (Pról. de José Monleón).

- (1993), Yo fui actor cuando Franco, Madrid, Fundamentos (Pról. de César Oliva).

- (1996), Gernika, un grito. 1937, Madrid, Fundamentos (Pról. de Mariano de Paco y epílogo de Eduardo Pérez-Rasilla).

- (2003), El chófer del teniente coronel von Richthofen toma decisiones, Madrid, AAT.

- (2005), Ederra, Madrid, Cátedra (Ed. de Eduardo Pérez-Rasilla).

BENET I JORNET, Josep M. (1980), Quan la ràdio parlava de Franco, Barcelona, Edicions 62.

CABAL, Fermín (1982), ¿Fuiste a ver a la abuela?, Madrid, Fundamentos (Pról. de Eduardo Haro Tecglen).

FERNÁN GÓMEZ, Fernando (1984), Las bicicletas son para el verano, Madrid, Espasa-Calpe (Pról. de Eduardo Haro Tecglen).

SANCHIS SINISTERRA, José (2000), ¡Ay, Carmela!, Madrid, Espasa-Calpe (Ed. de Eduardo Pérez-Rasilla).

- (2003): Terror y miseria en el primer franquismo, Madrid, Cátedra (Ed. de Milagros Sánchez Arnosi).

SIRERA, Rodolf y Josep Lluis (1993), Caballos de mar, Madrid, SGAE.

Fecha de recepción: 6 de mayo de 2008

Fecha de aprobación: 10 de octubre de 2008 